\title{
DESVELANDO O CONHECIMENTO DOS TRABALHADORES DE ENFERMAGEM ACERCA DOS RISCOS BIOLÓGICOS NA EMERGÊNCIA ${ }^{1}$
}

\section{REVEALING THE KNOWLEDGE OF THE WORKERS OF NURSING ABOUT THE BIOLOGICAL RISKS IN THE EMERGENCE}

\author{
Ana Carina da Cunha ${ }^{1}$ e Geilsa Soraia Cavalcanti Valente ${ }^{2 *}$ \\ ${ }^{1}$ Mestranda da Faculdade de Enfermagem/UERJ. anarjcunha@ hotmail.com; anarjcunha@gmail.com \\ ${ }^{2}$ Escola de Enfermagem Escola de Enfermagem Aurora de Afonso Costa/ UFF \\ *Membro da diretoria do Núcleo de Pesquisa Educação e Saúde em Enfermagem - NUPESENF da Escola \\ de Enfermagem Anna Nery - UFRJ.
}

\section{Resumo}

A equipe de enfermagem é considerada a mais exposta aos riscos ocupacionais e aos acidentes de trabalho. O objetivo desta pesquisa foi identificar o conhecimento dos profissionais quanto aos riscos biológicos a que estão expostos e, analisar formas de ações realizadas pelos trabalhadores de enfermagem para se prevenirem dos mesmos. A pesquisa é descritiva com análise qualitativa de dados. A coleta de dados foi realizada no setor de emergência de um hospital público no Rio de Janeiro, utilizando-se a entrevista semi-estruturada e a observação não participante.Os resultados foram agrupados em categorias: "1- A Percepção dos sujeitos acerca dos conhecimentos desenvolvidos na própria formação", e, 2- A percepção dos trabalhadores da equipe de enfermagem quanto à prevenção dos riscos biológicos."Concluiu-se que alguns fatores influenciam o conhecimento dos trabalhadores de enfermagem, como o interesse pessoal ou estímulo, falta de tempo, sobrecarga de trabalho, treinamentos inadequados, disponibilidade de EPIs e condições de trabalho.

Palavras-chave: Equipe de enfermagem; riscos biológicos; emergência.

\begin{abstract}
The team of nursing is considered the most exposed to the occupational risks and to the accidents of work. The objective of this inquiry was to identify the knowledge of professionals concerning the biological risks which they are exposed to and to analyse the forms of actions carried out by workers of nursing to be prevented of same. The inquiry is descriptive with qualitative analysis of data. The collection of data was carried out in the emergence room of a public hospital in Rio de Janeiro, when not participant observation is used and semi-structured interview takes part. The results were grouped in categories: "1-To Perception of subject about the knowledge developed in formation itself." "2-The perception of workers from the team of nursing as for the prevention of biological risks." To conclude, some factors influence the works of
\end{abstract}

\footnotetext{
${ }^{1}$ Trabalho extraído da monografia de conclusão do curso de graduação em Enfermagem apresentado a Universidade Estácio de Sá, 2005.
} 
nursing's knowledge, like the personal interest or stimulus, lack of time, overload of work, unsuitable trainings, availability of EPIs and conditions of work.

Keywords: Nursing team; biological risks; emergency.

\section{Introdução}

As instituições hospitalares se constituem locais de aglutinação de pacientes/clientes acometidos por diferentes problemas de saúde, assistidos por trabalhadores diversos, da área da saúde ou técnico-administrativas. Vários estudos têm apontado que os serviços de saúde, em particular os hospitais, geralmente proporcionam aos seus trabalhadores, principalmente da Enfermagem, piores condições de trabalho em relação a outros serviços (MARZIALE et al. apud BARBOZA e SOLER, 2003).

Com relação à análise dos aspectos que podem influenciar as atividades no trabalho, Barboza e Soler (2003) abordaram os fatores intra, peri e extralaborais, como: ambiente físico; riscos ocupacionais; higiene; estruturação e segurança do setor de trabalho; situação social de vida e do processo de trabalho do funcionário; organização e divisão das atividades; os meios disponíveis para o exercício profissional; jornada, turno, alimentação e transporte; situação social de moradia e deslocamento; interação pessoal e as relações entre produção e salário.

Durante o seu labor na emergência hospitalar, o enfermeiro fica exposto a inúmeros riscos ocupacionais, incluindo as precárias condições de trabalho que vão desde a área física, alta demanda e recursos humanos inadequados até a falta de material para realização de procedimentos.

Os acidentes com agulhas são caracterizados como um sério problema nas instituições hospitalares, uma vez que são os maiores responsáveis pela transmissão de infecções sanguíneas para os profissionais de saúde, principalmente por manutenção de práticas de risco sem utilização das precauções-padrão. Estima-se que após um acidente com agulha o risco de contaminação com o vírus da hepatite B (HBV) é de 6 a 30\%, com o vírus da hepatite $\mathrm{C}$ (HCV) é de 0,5 a 2\%, e com o vírus da AIDS (HIV) é de 0,3 a 0,4\%. A categoria profissional mais acometida por esse tipo de infortúnio é a dos auxiliares de Enfermagem, profissionais que estão em contato direto com o paciente, na maior parte do tempo, administrando medicamentos, realizando curativos e outros procedimentos que os mantêm em constante contato com material perfurante e cortante (BREVIDELLI; CIANCIARULLO, 2002). 
A ocorrência da doença depende das condições ou circunstâncias em que o trabalho é executado e da exposição ocupacional, que favorece o contato, o contágio ou a transmissão (BRASIL, 2001).

Portanto, esta pesquisa teve como objeto de estudo a exposição aos riscos biológicos dos trabalhadores de Enfermagem que atuam na emergência de um hospital público do Rio de janeiro.

Dentre os fluidos corporais, tem-se reconhecido o sangue como o mais importante veículo de transmissão ocupacional dos vírus da Hepatite B (HBV), Hepatite C (HCV) e AIDS (HIV), sendo que o maior risco para os trabalhadores da área de saúde é o acidente com material perfurocortante, que expõe os profissionais a microorganismos patogênicos, sendo a Hepatite B a maior incidência entre esses trabalhadores (SHAPIRO apud CANINI et al., 2002).

A equipe de Enfermagem convive com variados fatores de risco durante todo o período de trabalho no setor de emergência dos hospitais públicos (sem muitas vezes utilizar equipamentos de proteção individual adequados - EPIs). Os objetivos neste estudo foram: Identificar o grau de conhecimento dos profissionais quanto aos riscos biológicos a que estão expostos; e, Analisar formas de ações realizadas pelos trabalhadores de Enfermagem para se prevenirem dos riscos biológicos.

O estudo em questão justifica-se pelo fato de ter sido acadêmica bolsista de um Hospital Estadual no setor de emergência e ter observado inúmeros riscos de acidentes de trabalho. Sabe-se que, nos setores públicos, muitas vezes se tem deficiência de materiais necessários para a proteção individual. Portanto, nem sempre o treinamento da equipe de Enfermagem para a prevenção de acidentes é eficaz em decorrência de vários fatores, como por exemplo, o interesse do próprio trabalhador, a existência de material em quantidade suficiente para atender as demandas do trabalho, dentre outros.

A falta de importância dada às pequenas lesões, tais como picada de agulha, e o desconhecimento sobre a importância da emissão da CAT (Comunicação de Acidente de Trabalho), foram apontadas como causas da subnotificação de acidentes de trabalho na visão de trabalhadores de Enfermagem de uma cidade do interior paulista (MARZIALE; RODRIGUES, 2002).

Por isso, torna-se indispensável o treinamento, a educação continuada e a conscientização da equipe quanto ao uso dos equipamentos de proteção individual adequados ao tipo de procedimento a ser realizado. 
Segundo a Resolução do Conselho Federal de Medicina nº 1451 / 95, EMERGÊNCIA é definida como a constatação médica de condições de agravo à saúde que impliquem em risco iminente de vida ou sofrimento intenso, exigindo, portanto, tratamento médico imediato. Ainda, segundo o artigo $5^{\circ}$ o estabelecimento de Pronto Socorro deverá permanecer à disposição da população em funcionamento ininterrupto (BRASIL, 1995).

Os profissionais que trabalham no setor de emergência expõem-se significativamente aos riscos ocupacionais devido a grande rotatividade dos pacientes sem histórico prévio, ao dinamismo e agilidade inerentes ao atendimento prestado neste local. Através desse estudo, pretendeu-se entender a visão dos profissionais quanto aos riscos, e o que pensam sobre esta exposição.

A relevância do estudo em questão está em investigar o conhecimento dos trabalhadores de Enfermagem sobre os riscos biológicos a que estão expostos e, se esse conhecimento é suficiente para que as medidas de biossegurança sejam seguidas.

\section{Metodologia}

Realizou-se uma pesquisa descritiva com abordagem qualitativa no tratamento dos dados. Este levantamento ocorreu no setor de emergência de num hospital público de grande porte do Rio de Janeiro, através da entrevista semi-estruturada associada à observação não-participativa (LAKATOS; MARCONI, 2001).

Este levantamento ocorreu no setor de emergência de num hospital público de grande porte do Rio de Janeiro, através da entrevista semi-estruturada associada à observação não-participativa. No momento da entrevista, as respostas foram anotadas e registradas com o uso de gravador com a prévia permissão do sujeito a fím de reproduzir as respostas com precisão (GIL, 1999).

Participaram do estudo 2 enfermeiros, 3 técnicos e 4 auxiliares de Enfermagem, que concordaram em participar da pesquisa e assinaram o Termo de Consentimento Livre e Esclarecido. A pesquisa foi autorizada previamente pela instituição. E, a Resolução 196/96 foi respeitada, onde os participantes foram identificados por nomes de flores permitindo a análise de dados de forma anônima (BRASIL, 1996; RAMPAZZO, 2004).

A pesquisa foi autorizada previamente pela instituição. E, a Resolução 196/96 foi respeitada, onde os participantes foram identificados por nomes de flores permitindo a análise de dados de forma anônima. 


\section{Resultados e Discussão}

Com base na análise temática de conteúdo, os dados foram agrupados em duas categorias e respectivas subcategorias. 1-Percepção dos sujeitos acerca dos conhecimentos desenvolvidos na própria formação e 1.1-A Percepção dos trabalhadores da equipe de Enfermagem quanto à exposição aos riscos biológicos. 2-A percepção dos trabalhadores da equipe de Enfermagem quanto à prevenção dos riscos biológicos e 2.1 Acidente com material biológico: Quais as providências que devem ser tomadas?

Os sujeitos foram identificados por: Margarida, Rosa, Tulipa, Cravo, Orquídea, Jasmim, Violeta, Azaléa e Crisântemo. Algumas variáveis dos sujeitos estão expostas no quadro abaixo para que se possa correlacioná-las com o conhecimento desses profissionais acerca dos riscos biológicos que é o enfoque da pesquisa, levando em consideração a formação profissional e experiência no setor de emergência.

\begin{tabular}{|c|c|c|}
\hline Variáveis & Resposta & Freqüiência \\
\hline Cargo & Auxiliar de enfermagem & 04 \\
& Técnico de Enfermagem & 03 \\
& Enfermeiro & 02 \\
\hline Sexo & Masculino & 01 \\
& Feminino & 07 \\
Tempo de atuação no & 6 meses a 1 ano & 02 \\
setor de emergência & $2-3$ anos & 02 \\
& $3-4$ anos & 01 \\
& $4-5$ anos & 02 \\
\hline
\end{tabular}

Quadro 1: Dados do perfil dos profissionais participantes do estudo.

\section{1-Percepção dos sujeitos acerca dos conhecimentos desenvolvidos na própria formação}

A solidificação do conhecimento e a busca incessante de novas informações deveriam fazer parte da vida profissional, porém, observa-se que alguns trabalhadores se acomodam em seus "saberes" e deixam de buscar as atualizações necessárias ao bom desempenho profissional. É difícil conscientizar a respeito deste processo, mas estratégias podem ser utilizadas para estimular os profissionais. Com relação à freqüência aos cursos de atualização entre os entrevistados, obtivemos as seguintes respostas: 
...No momento, não tenho freqüentado cursos de atualização... (pausa). Estou fazendo complementação, mas é particular...(Rosa)

Pode-se perceber que Rosa, apesar de não freqüentar cursos de atualização, busca conhecimentos através da complementação de sua formação profissional.

Aqui?... Não....(pausa longa). Nunca teve...Aqui...(pausa curta).O curso que tem aqui é de eletro que ninguém sabe... O eletro está quebrado, o pessoal diz que está bom... E uns cursinhos existentes aqui...que até o médico tem que fazer e não faz..... (Margarida)

Não...Porque aqui eles vivem prometendo pra gente e nunca tem...(pausa longa). Eles só prometem... (Orquídea)

Quando tem aqui...Eu freqüento,...Eu tenho 6 anos aqui e freqüentei $2 \ldots O$ último curso foi há 2 anos mais ou menos. (Azaléa)

Verificou-se nos relatos acima, a dependência de ofertas de cursos pela instituição, dando a entender que é uma obrigação da mesma. Portanto para estes sujeitos, a busca de conhecimentos não é considerada como forma de crescimento pessoal e, conseqüentemente, como estratégia de prevenção quanto aos riscos biológicos, o que traz influência negativa no que tange aos riscos ocupacionais, pois só é possível a precaução quando há conhecimento.

Durante a pesquisa foram observados panfletos de alguns cursos para funcionários nos murais dos corredores, e o curso sobre acidentes biológicos chamou a atenção. Então, este fato sinalizou que os cursos existiam, porém a falta de horários alternativos ou desinteresse dos funcionários acarretaram respostas como a falta ou escassez de cursos ofertados pela instituição e falta de tempo.

Não...(pausa longa). É, ultimamente não tem dado tempo,...Quase não tem dado tempo porque saio de um serviço e vou para outro,...E, praticamente eu estou tendo um dia de folga na semana (Jasmim).

Dentre os 09 sujeitos da pesquisa, somente quatro costumavam freqüentar cursos de atualização, sendo que 02 trabalhavam em outros locais que ofereciam cursos e por isso o faziam quando havia oportunidade, porém muitos se justificavam com a falta de tempo para não freqüentar nenhum tipo de curso. 


\section{1- A Percepção dos trabalhadores da equipe de Enfermagem quanto à exposição aos riscos biológicos}

O Ministério da Saúde (BRASIL, 2001) caracteriza as doenças infecciosas e parasitárias relacionadas ao trabalho aos agentes etiológicos serem de natureza ocupacional, a dependência das condições em que o trabalho é realizado e o grau de exposição. Com relação ao trabalho específico dentro da instituição hospitalar as exposições que podem trazer riscos de transmissão ocupacional com maiores conseqüências são: HIV e dos vírus da hepatite B (HBV) e C (HCV), além da tuberculose.

As consequiências para a saúde da exposição do trabalhador a fatores de risco biológico presentes em situações de trabalho incluem quadros de infecção aguda e crônica, parasitoses e reações alérgicas e tóxicas (BRASIL, 2001).

Esta subcategoria foi criada porque houve a necessidade de se pesquisar sobre o grau de conhecimento que os sujeitos tinham a respeito das patologias que eles se sentiam expostos no seu local de trabalho. Responderam o seguinte:

Hepatite, tuberculose, HIV e meningite, entre outras que não tão...Essas daí são doenças que pode ter forma de contágio...Mas tem DPOC e outras doenças também...Mas as principais são essas...Existe também o MRSA...

(Crisântemo)

A exposição cutânea como o contato com feridas abertas ou com pele com dermatite (pele não íntegra) constitui um risco de transmissão de HIV e Hepatites B e C, porém este risco pode ser nulo ao se utilizar luvas durante a manipulação.

$\mathrm{Na}$ fala de Orquídea percebeu-se que a mesma mencionou como riscos a pediculose e escabiose (doenças parasitárias), que apesar de não serem consideradas pelo Ministério da Saúde (BRASIL, 2001) como doença ocupacional para trabalhadores da área de saúde com maiores conseqüências, este risco torna-se evidente ao observar o local de trabalho em que, oficialmente a capacidade era de 14 leitos, e no momento existiam cerca de 25 leitos, além das pessoas que estavam sendo atendidas nos bancos, constituindo condições inseguras de trabalho, além de falta de material para a adequada realização de técnicas. O cuidado neste cenário tornou-se mais propício para a ocorrência de acidentes, além da proximidade não só dos pacientes, como também destes com quem prestava a assistência, possibilitando a disseminação da pediculose e escabiose. 
As contagiosas, todas elas...Mas a que eu tenho medo é a hepatite...BK,...A gente nunca sabe o que é por ser um hospital de emergência..., HIV, hepatite, escabiose...De mais, tem muito aqui...pediculose...São as mais comuns. (Orquídea)

A exposição ao vírus da hepatite foi mencionado por 6 participantes mas nenhum deles especificou os tipos de hepatite, e somente um sujeito mencionou a vacinação como forma de prevenção para hepatite B.

Apesar de ser setor de emergência e que deveria ser de curta permanência, o que se observou, na verdade, é uma grande enfermaria de clínica médica superlotada em que os pacientes ficavam internados durante longo período de tempo aguardando vaga para outros setores.

Alguns trabalhadores demonstraram preocupação em relação à exposição ocupacional em virtude da demora de diagnóstico do paciente, que muitas vezes estão em antibioticoterapia há dias de patologias que necessitam de isolamento como a tuberculose e meningite, além de uso de EPI adequado.

Equivocadamente, o lupus, a psoríase e outras patologias auto-imunes foram mencionadas, mas que a princípio não oferecem riscos aos trabalhadores, assim como Doença Pulmonar Obstrutiva Crônica (DPOC). Isto refletiu o desconhecimento sobre as patologias que representam real risco de contaminação e a distinção daquelas em que não há risco algum, a não ser que estejam associadas a outras patologias.

Pneumonia é um termo genérico e, em ambiente hospitalar não é mencionada pelo Ministério da Saúde (BRASIL, 2001) como doença relacionada ao trabalho, exceto quando causada por agentes com alto risco de transmissão. Por exemplo, o bacilo anthracis que acomete trabalhadores de lã que se infectam com materiais contaminados, evoluindo com pneumonia, septicemia e morte.

O MRSA (Staphylococcus Aureus Meticilino Resistente) foi bastante mencionado entre os trabalhadores que se sentiam expostos e demonstraram medo da contaminação, fato este inverídico, pois este possui característica transitória de vias aéreas superiores com pouca transmissibilidade para os profissionais de saúde. Porém, importantíssimo o isolamento de contato com relação aos demais clientes.

A existência de outras patologias com maior risco de contágio como o HIV e hepatite $\mathrm{C}$ não foram mencionadas por uma parcela dos entrevistados, das quais os sujeitos demonstraram falta de conhecimento ou importância. 
A hanseníase se torna risco quando o paciente não é tratado, pois o bacilo é morto e incapaz de infectar outras pessoas, logo no início do tratamento com a poliquimioterapia (PQT-Rifampicina, Dapsona e Clofazimina), que é realizado em Unidades Básicas de Saúde (BRASIL, 2002).

\section{2- A percepção dos trabalhadores da equipe de enfermagem quanto à prevenção dos riscos biológicos}

Esta categoria foi elaborada para análise dos EPIs utilizados pelos profissionais entre outras medidas preventivas e, se essas medidas eram realizadas em sua prática profissional.

Rapparini; Vitória; Lara (2004) recomendam o uso rotineiro de barreiras de proteção (luvas, capotes, óculos de proteção ou protetores faciais) quando o contato muco-cutâneo com sangue ou outros materiais biológicos, incluindo precauções necessárias na manipulação de agulhas e outros materiais cortantes.

Aqui a gente trabalha com o mínimo essencial... Mas a gente trabalha aqui com luva e máscara quando tem... Não tem outro tipo de equipamento de proteção individual. A gente trabalha aqui com as duas máscaras, a cirúrgica que não adianta de nada, mas a gente tem aquela outra, a bico de pato. (Cravo)

Uso de luva, óculos de proteção, máscara... Essas máscaras descartáveis. E, você usar 2 luvas eles diziam...2 luvas mas não é proteção completa, mas alguns usam pra ter aquele...mais psicológico... Você usar uma luva só, de preferência de procedimento que não seja fina demais que é o que não ocorre aqui... Que ela é fina demais e rasga...Perco o tato ...É o que acontece, primeiro comigo por causa da luva grande...(Margarida)

Na fala de Margarida ficou nítida a insegurança com relação à qualidade do material das luvas de procedimento, além do uso e tamanho inadequados quando fala em: “...usar 2 luvas..”, apesar de saber que não é o correto, e “...luva grande...”, havendo perda de sensibilidade para realização dos procedimentos de enfermagem.

Durante a observação constatou-se que o único EPI utilizado era luva de procedimento e estéril, e que muitos dos entrevistados não faziam uso da mesma durante a punção venosa. O fio guia, de um modo geral era deixado ou fixado no colchão durante o procedimento. A máscara disponível era a cirúrgica, porém elas 


\section{Cunha e Valente}

estavam sendo utilizadas nos pacientes com suspeita de tuberculose, enquanto as do tipo bico de pato (N 95) ficavam reservadas na sala da Chefia de Enfermagem e de acesso restrito pela quantidade insuficiente para todos os funcionários.

A máscara cirúrgica em momento algum foi utilizada pelos participantes, nem mesmo em procedimentos com possibilidade de contato com secreções vesicais, como no cateterismo, ou em troca de curativo de grande proporção em úlcera por pressão de região sacra. A proteção de mucosa ocular foi literalmente esquecida pelos sujeitos da pesquisa, sendo mencionado os óculos uma única vez.

Com relação à tuberculose, faz-se necessário a ventilação local como forma de evitar a contaminação, fato este que não ocorreu, visto que até o ar condicionado não é capaz de promover troca de ar por causa da superlotação. Nesses casos, é indicado o uso de quarto privativo e, se possível, com ventilação especial, por meio da pressão negativa e da filtração do ar com filtro de alta eficiência (HEPA - High Efficiency Particulate Air).

Nos quartos privativos, as portas e janelas devem ser mantidas fechadas e o profissional deve utilizar máscara com filtro para partículas menores que 5 micras (N95), ou seja, 95\% de eficiência na filtragem de microrganismos. Estas máscaras são conhecidas como "bico de pato", e podem ser reutilizadas por longos períodos pelo mesmo profissional, desde que se apresente íntegra, seca, limpa e com boa ventilação (SCHEIDT; ROSA; LIMA, 2006; LEVIN et al., 2006).

As máscaras cirúrgicas comuns não fornecem proteção adequada quando utilizadas pelos profissionais, ficando seu uso restrito na contenção de partículas no momento em que são geradas e pode ser utilizada pelo paciente bacilífero quando houver necessidade de transporte do mesmo ou fora dos locais de isolamento (LEVIN et al., 2006).

Outro fato observado foi a falta de oferta de luvas de procedimento para o adequado atendimento, em que o plantão começava às 7:00 da manhã e as luvas e demais materiais chegavam no setor cerca de uma a duas horas depois. Durante este período de tempo os funcionários trabalhavam sem luvas quando não havia luvas estéreis para suprir esta carência.

Com relação ao descarte de material perfurocortante, as agulhas e fios guias estavam sendo descartados em caixas de papelão improvisadas, sendo que nestas caixas não há camada rígida dupla e, muito menos a impermeabilidade das caixas adequadas.

Os cascos das medicações injetáveis eram descartados no lixo comum, 
constituindo em risco para o pessoal da limpeza, visto que neste mesmo lixo eram colocados os curativos trocados, gaze com sangue e etc. Este material biológico poderia contaminar os cascos e, por conseqüência, em caso de acidente, contaminar a equipe de limpeza de plantão.

Segundo o Ministério da Saúde (BRASIL, 2000), os coletores específicos para o descarte de material perfurocortante não devem ser preenchidos acima de $2 / 3$ de sua capacidade total e ter localização próxima do local onde o procedimento é realizado. $\mathrm{Na}$ prática isto não ocorria, pois os coletores ficavam nos postos de Enfermagem, porém não havia equipamento disponível para o transporte seguro deste material até o coletor.

A lavagem das mãos, como forma de evitar contaminação era praticamente nula neste setor, até mesmo por causa da planta física local e a superlotação, fato este constatado na observação.

\section{1- Acidente com material biológico: Quais as providências que devem ser tomadas?}

Ao serem questionados se já haviam sofrido algum tipo de acidente com perfurocortantes, descobriu-se que quase $45 \%$ dos participantes já haviam sofrido este tipo de acidente em alguma fase de sua vida profissional.

Fui atrás do enfermeiro chefe do plantão, descobrir se tinha o medicamento de ataque e depois, uma maratona para poder conseguir fazer pelo menos uma semana de medicação e eu consegui fazer, só que até hoje ninguém me perguntou se eu fiz tudo...(Margarida)

Ficou evidente na fala de Margarida, em que a mesma alega a distração como causa do acidente, além é claro de um erro técnico e ato inseguro de reencapar a agulha. Percebeu-se que a mesma possuía o conhecimento sobre riscos e mesmo assim insistiu em praticá-los, algo que foi confirmado durante a observação de seu trabalho.

O Ministério da Saúde (BRASIL, 2000) recomenda que, durante a realização de procedimentos que envolvam a manipulação de perfurocortantes, deve-se ter máxima atenção, jamais utilizar os dedos como anteparo, as agulhas jamais devem ser reencapadas e, descartados em recipientes adequados.

O abalo psicológico, e o sentimento de medo ficaram evidentes quando analisadas as falas de dois sujeitos da pesquisa que já haviam sofrido um acidente.

... Eu falei: Ai, Jesus, vou morrer...(Margarida) 
...Fiquei andando feito uma barata tonta, chorando e com medo, porque tinha duas horas para iniciar o tal do coquetel...(Orquídea)

Segundo Rapparini; Vitória; Lara (2004), quando a quimioprafilaxia pós exposição ocupacional é indicada, deve ser iniciada o mais rápido possível, idealmente, nas primeiras horas após o acidente. Recomenda-se o prazo máximo de até $72 \mathrm{~h}$ após o acidente. A duração da quimioprofilaxia é de 28 dias.

Aí eu perguntei se tinha a medicação de ataque... Ah tem, mas a chave está com beltrano, com cicrano,... Mas o certo seria fazer em duas horas... Eu levei quase um dia inteiro... (Margarida)

De acordo com a conduta após exposição ocupacional ao HIV, o teste anti HIV é realizado no paciente fonte e, dentro de $72 \mathrm{~h}$ o profissional é reavaliado. Isto nos leva a acreditar que a conduta realizada a princípio estava correta, e ficou falho na medida em que o hospital não tinha medicação disponível. Este fato foi mencionado não só na fala de Orquídea como na de Margarida, comprometendo a eficácia da quimioprofilaxia.

Segundo Carvalho (2001) o acidente do trabalho deve ser comunicado à empresa imediatamente, quando possível pelo acidentado, e a empresa deve comunicar o acidente ao INSS (Instituto Nacional de Seguro Social) dentro de 24 horas, sob pena de multa, que é aplicada e cobrada pela previdência social.

De acordo com os relatos, concluiu-se que o fluxograma para o profissional acidentado é conhecido por todos os profissionais entrevistados, porém a oficialização do acidente com emissão da CAT e a obrigatoriedade da notificação dentro de $24 \mathrm{~h}$, quando possível, constitui um universo desconhecido para esses trabalhadores.

Em novembro de 2005 foi aprovada a Norma Regulamentadora 32 que trata especificamente do trabalho realizado em serviços de saúde, onde estão as recomendações necessárias e que envolvem deste a estrutura física do ambiente de trabalho, equipamentos de proteção, emissão de CAT e treinamento. Além desta norma há determinações que compõem outras legislações e que devem ser observadas nestes locais de trabalho (BRASIL, 2005).

\section{Conclusão}

Os resultados mostraram que, independente do cargo que ocupam, os profissionais que se preocupavam com a continuidade da formação profissional, freqüentando cursos de atualização, entre outros, sentiram-se mais seguros em participar 
da pesquisa. Porém isto não demonstrou conhecimento adequado com relação aos riscos biológicos.

Por outro lado, a falta de disponibilidade de tempo foi mencionada como um dos fatores que impediam a realização de cursos de atualização, além da falta de oferta pela instituição. Acreditamos que a busca de conhecimento não deve ser dependente de outra pessoa, deveria fazer parte da vida de todos os profissionais, principalmente na área de saúde, onde o conhecimento pode significar precaução.

Ficou claro o total desconhecimento sobre algumas patologias como MRSA, em que a precaução de contato resguarda a saúde do outro paciente, e não a do trabalhador devido a sua pouca transmissibilidade e característica transitória de vias aéreas superiores, enquanto existem outras patologias de maior risco de contágio.

Doenças auto-imunes foram citadas, como lupus e psoríase, e também DPOC demonstrando a falta de informação, pois não são infecto-contagiosas. A pneumonia não é considerada como risco potencial para a equipe de enfermagem a não ser que haja outras patologias associadas.

O quantitativo de pessoal deficiente e setores superlotados acarretam sobrecarga de trabalho e interfere na liberação do profissional para que este possa realizar um treinamento com tranqüilidade ou participar de cursos de atualização, além é claro dos baixos salários que acarretam dupla ou tripla jornada de trabalho.

As condições de trabalho e os estímulos relacionados ao aprimoramento profissional também deveriam partir das autoridades responsáveis pela saúde, a nível municipal, estadual e federal, melhorando a qualidade do atendimento da população e proporcionando maior segurança aos trabalhadores de Enfermagem.

Com relação às formas de ações realizadas pelos trabalhadores de Enfermagem para se prevenirem dos riscos biológicos, referentes ao segundo objetivo deste estudo, concluímos que o saber dos profissionais ainda é incipiente na área de biossegurança. A associação entre o tipo de patologia, mecanismo de transmissão e a utilização de EPI adequado é realizada, ainda que de forma rudimentar.

\section{Referências}

BARBOZA, D. B., SOLER, Z. A. S. G. Afastamentos do trabalho na enfermagem: ocorrências com trabalhadores de um hospital de ensino. Rev. Latino-am de Enfermagem, Ribeirão Preto, v.11, n. 2, p.177-183, mar/abr. 2003. 
BRASIL. Conselho Federal de Medicina. Resolução nº 1451 / 95. Diário Oficial da República Federativa do Brasil, Brasília, 17 de março de 1995. Disponível em: <http://www.portalmedico.org.br/resolucoes/cfm/1995/1451_1995.htm>. Acesso em: 03 set. 2009.

BRASIL. Ministério da Saúde. Doenças relacionadas ao trabalho - Manual de Procedimentos para os Serviços de Saúde: Série A. Normas e Manuais Técnicos; Brasília/DF - Brasil: n. 114. 2001.

BRASIL. Ministério da Saúde. Exposição ocupacional à material biológico: Hepatite e HIV. Manual de Condutas $2^{\text {a }}$ ed: Brasília-DF, 2000.

BRASIL. Ministério da Saúde. Recomendações para tratamento da co-infecção entre HIV e Hepatites virais: Brasília-DF. 2002.

BRASIL. Ministério do Trabalho e Emprego. Portaria $n^{\circ}$ 485, de 11 de Novembro de 2005. NR 32- Segurança e Saúde no Trabalho em Serviços de Saúde. Diário Oficial da União, Seção 1, Brasília/DF, de 16 de Novembro de 2005.

BRASIL. Resolução 196, de 10 de outubro de 1996. Dispõe sobre diretrizes e normas regulamentadoras de pesquisas envolvendo seres humanos. Conselho Nacional de Saúde. Brasília, DF. Disponível em: < http://conselho.saude.gov.br/docs/Reso196.doc > Acesso em 03 set. 2009.

BREVIDELLI, M. M.; CIANCIARULLO, T. I. Análise dos acidentes com agulhas em um hospital universitário: situações de ocorrência e tendências. Rev. Latino-am de Enfermagem, Ribeirão Preto, v.10, n.6, p.780-786, nov/dez. 2002.

CANINI, S. R. M S; GIR, E.; HAYASHIDA, M. e MACHADO, A. A. Acidentes perfurocortantes entre trabalhadores de enfermagem de um hospital universitário do interior paulista. Rev. Latino-am de Enfermagem, Ribeirão Preto, v.10, n.2, p.172-178, mar/abr. 2002.

CARVALHO, G. M. Enfermagem do Trabalho. 5 ed. São Paulo: EPU, 2001.

GIL, A. C. Métodos e técnicas de pesquisa social. 5ed. São Paulo: Atlas. 1999.

LAKATOS, E. M.; MARCONI, M.A. Fundamentos de metodologia científica. 4 ed. São Paulo: Atlas, 2001.

LEVIN, A. S. S.; LEITE, O. H. M.; DIAS, M. B. S.; OLIVEIRA, M. S.; LOBO, R. D. Tuberculose padronização de condutas: normas para o diagnóstico, tratamento e prevenção da tuberculose. São Paulo: Hospital das Clínicas FMUSP, 2006.

MARZIALE, M. H. P.; RODRIGUES, C. M. A produção científica sobre os acidentes de trabalho com material perfurocortante entre trabalhadores de enfermagem. Rev. Latino-am de Enfermagem, Ribeirão Preto, v.10, n.4, p.571-577, jul/ago. 2002.

RAMPAZZO, L. Metodologia científica - Para alunos dos cursos de graduação e pósgraduação. 2 ed. São Paulo: Loyola. 2004. 
RAPPARINI, C.; VITÓRIA, M. A. A.;.LARA, L. T. R. Recomendações para atendimento e acompanhamento da exposição ocupacional a material biológico : HIV, hepatites B e C, 2004. Disponível em: <

http://www.saude.rio.rj.gov.br/media/manual_acidentes.pdf>. Acesso em: 03 set. 2009.

SCHEIDT, K. L. S.; ROSA, L. R. S.; LIMA, E. F. A. As ações de biossegurança implementadas pelas comissões de controle de infecções hospitalares. R. Enferm UERJ, Rio de Janeiro, v. 14, n. 3, p. 372-77, jul/set. 2006. 